\title{
Postoperative right ventricular dysfunction-Integrating right heart profiles beyond long-axis function
}

André Denault, MD, PhD, FRCPC, ABIM-CCM, FASE, FCCS, ${ }^{\text {a }}$ Francois Haddad, MD, FRCPC, FAHA, ${ }^{b}$ Yoan Lamarche, MD, MSc, FRCSC, ${ }^{\mathrm{c}}$ Nadia Bouabdallaoui, MD, ${ }^{\mathrm{d}}$ Alain Deschamps, MD, PhD, FRCPC, and Georges Desjardins, MD, FRCPC, FASE ${ }^{a}$

\footnotetext{
From the Departments of ${ }^{\mathrm{a}}$ Anesthesia \& Critical Care Division, ${ }^{\mathrm{c}}$ Cardiac Surgery, and ${ }^{\mathrm{d}}$ Medicine, Montreal Heart Institute, Université de Montréal, Montreal, Quebec, Canada; and ${ }^{\mathrm{b}}$ Department of Cardiovascular Medicine, Stanford University, Stanford, Calif.

Disclosures: Dr Denault has been a speaker for CAE-Healthcare (2010) and Masimo (2017) and has received an equipment grant from Edwards (2019). All other authors have nothing to disclose with regard to commercial support.

Received for publication May 15, 2019; revisions received May 15, 2019; accepted for publication May 16, 2019; available ahead of print July 10, 2019.

Address for reprints: André Denault, MD, PhD, Montreal Heart Institute, 5000 Belanger St, Montreal, Quebec H1T 1C8, Canada (E-mail: andre.denault@umontreal.ca).

J Thorac Cardiovasc Surg 2020;159:e315-7

0022-5223/\$36.00

Copyright (C) 2019 by The American Association for Thoracic Surgery

https://doi.org/10.1016/j.jtcvs.2019.05.064
}

Right ventricular (RV) failure has been long recognized by cardiac surgeons as a major cause of morbidity and mortality. ${ }^{1-7}$ Through the years, studies have focused on identifying more sensitive markers of RV dysfunction. The study of Singh and colleagues ${ }^{8}$ in this issue of the Journal brings novel insights into perioperative changes in RV function, focusing on annular, longitudinal shortening (RV myocardial strain) as well as area changes. Its strength lies in describing the dynamic of RV changes at key perioperative moments and in variable types of surgery. Almost 30 years ago, Popp and associates ${ }^{9}$ observed impairment in tricuspid annular excursion following cardiac surgery. One important question raised by this observation was whether longitudinal RV function reflects global systolic function. In fact, one of the challenges in assessing RV function resides it its complex geometry. By means of 3dimensional echocardiography, Tamborini and coworkers ${ }^{10}$ showed that despite the postoperative reduction of tricuspid annular excursion, 3-dimensional RV ejection fraction remained preserved at 3 postoperative months. The study of Singh and colleagues ${ }^{8}$ also demonstrates that RV fractional area change is less impaired than annular or strain indices, at least in patients undergoing coronary revascularization.

Systolic parameters are, however, only one component of right heart performance. ${ }^{11}$ Other components can be divided as consequences or mechanism of RV failure (Figure 1). Hemodynamic elements, such as central venous pressure and the mean pulmonary arterial pressure to systemic arterial pressure ratio (yielding insights into both the pulmonary and systemic circulations ${ }^{13-17}$ ) are useful to monitor; however, combined pulmonary artery and RV pressure waveform (Figure 1, $A)^{18}$ appears to be a promising method for detecting abnormal RV function. ${ }^{19}$ The current understanding of RV failure combines the

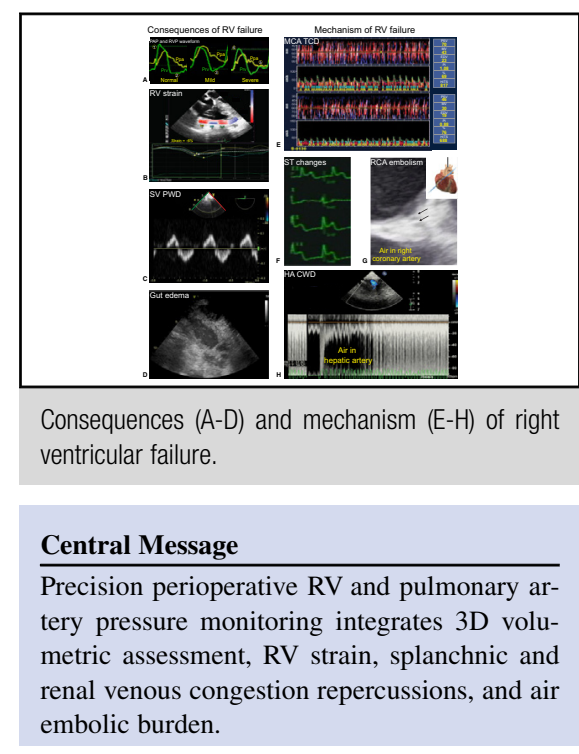

See Article page 1430 in the April 2020 issue.

ventricular and the arterial elastance as an index of RVarterial coupling. ${ }^{20}$ When this $\mathrm{RV}$-arterial coupling is less than 1, then the RV will enlarge to maintain cardiac output, but at the expense of venous congestion.

This concept in recent years has led to an emphasis beyond systolic and diastolic RV parameters toward both forward (low cardiac output) and backward (venous congestion) consequences of RV dysfunction. This can lead to a vicious cycle of decreased overall tissue perfusion and congestion to the brain, liver, spleen, gut, and kidney ${ }^{21,22}$ (Figure 1, $B$ through $D$ ) In 2 recent prospective studies in which portal venous flow Doppler was interrogated before, during, and after cardiac surgery, ${ }^{23,24}$ the presence of portal pulsatility greater than $50 \%$ (used as a surrogate for splanchnic congestion) was associated with all the commonly used hemodynamic and echocardiographic variables related to RV dysfunction. In addition, both abnormal portal and renal venous pulsatilities were associated with prolonged duration of stay in the intensive care unit, excessive bleeding, reoperation, acute renal failure, and increased overall complication rate. ${ }^{23,24}$

Finally, air embolization (Figure 1, $E$ through $H$ ) should always be considered as contributing mechanism of RV 


\section{Consequences of RV failure}
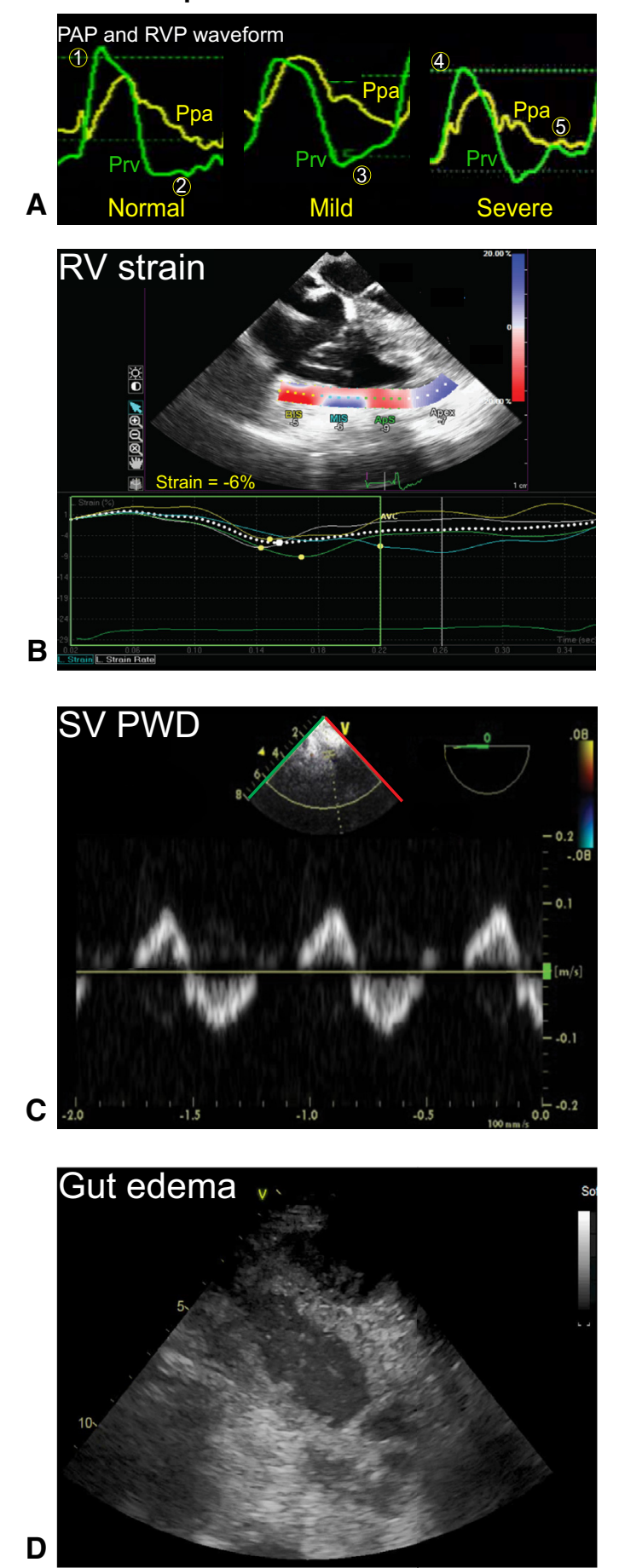

\section{Mechanism of RV failure}
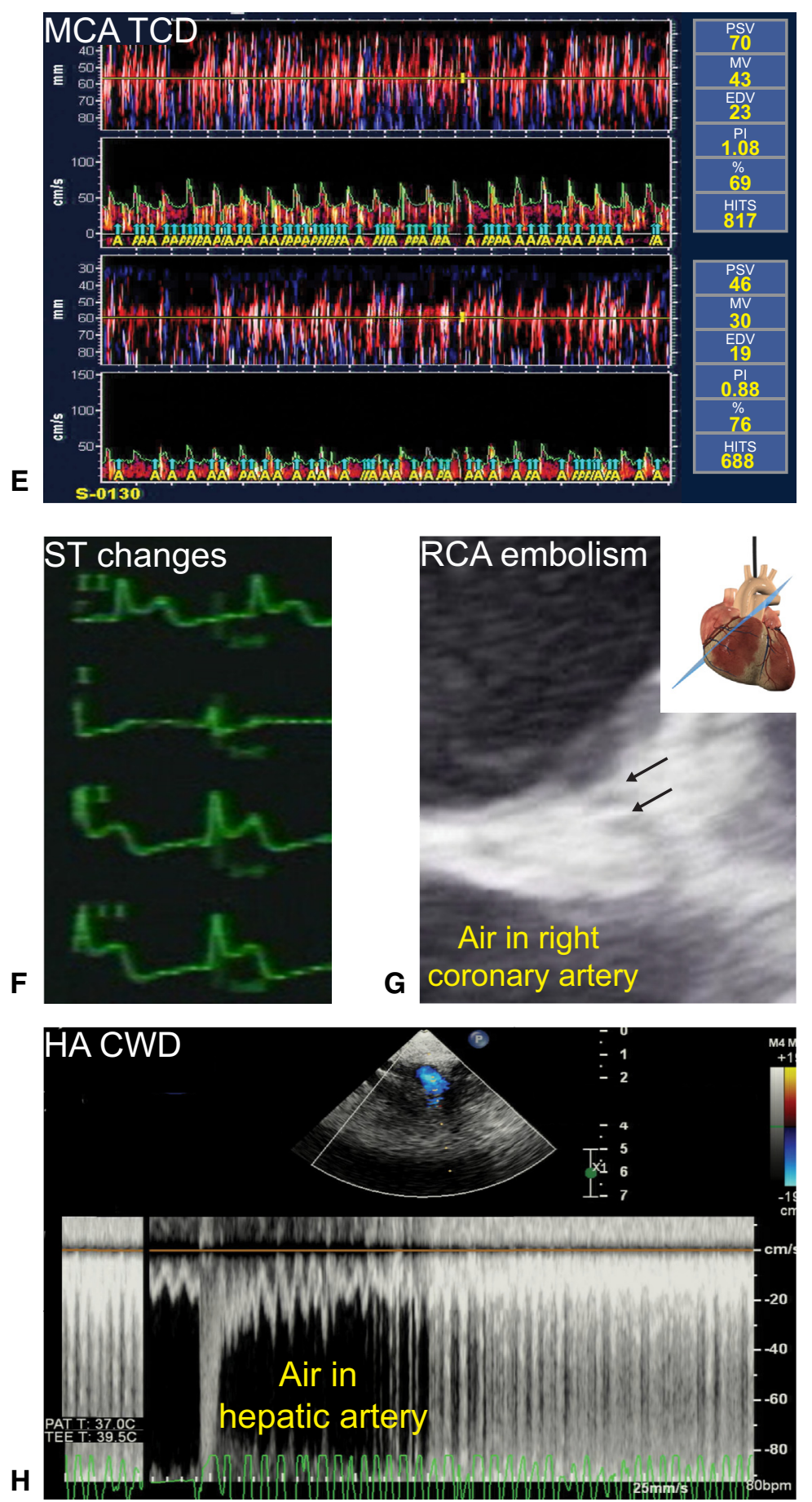

FIGURE 1. Consequences (A-D) and mechanisms (E-H) of right ventricular $(R V)$ failure. A, Simultaneous pulmonary artery pressure $(P A P)$ and right ventricular pressure $(R V P)$ waveforms. Numbered features: 1 , Normal right ventricular pressure ( $P r v$ ) waveform with rapid systolic pressure changes; 2 , normal horizontal Prv diastolic slope; 3, abnormal right ventricular pressure Prv diastolic slope greater than $4 \mathrm{~mm} \mathrm{Hg;} \mathrm{4,} \mathrm{square} \mathrm{root} \mathrm{sign} \mathrm{with} \mathrm{RV} \mathrm{pulsus} \mathrm{tardus;} 5$, diastolic equalization between the Prv and the diastolic pulmonary artery pressure (Ppa). BIS, Basal inferior section; $M I S$, midinferior section; APS, apical section; $A V C$, aortic valve closure; $S V$, splenic vein; $P W D$, pulsed-wave Doppler; $M C A$, middle cerebral artery; $T C D$, transcranial Doppler; $P S V$, peak systolic velocity; $M V$, mean velocity; $E D V$, end-diastolic velocity; $P I$, pulsatility index; HITS; high-intensity transient signals; $R C A$, right coronary embolism; $H A$, hepatic artery; $C W D$, continuous-wave Doppler. Adapted by permission of Taylor and Francis Group, LLC, a division of Informa plc, from: Denault A, Vegas A, Lamarche Y, Tardif J, Couture P. Basic Transesophageal and Critical Care Ultrasound. Taylor and Francis, CRC Press, Boca Raton, FL. 2018. ${ }^{12}$ 
dysfunction after cardiac surgery. Beyond direct visualization of air emboli in the coronary artery, ST elevation in the inferior lead on weaning form cardiopulmonary bypass with simultaneous hyperintensity transient signals in the middle cerebral artery on transcranial Doppler ${ }^{25,26}$ and in the hepatic artery may also be suggestive of such a mechanism.

In conclusion, we are currently entering an era of precision right heart monitoring. This monitoring integrates RV and pulmonary artery pressure monitoring, 3dimensional volumetric and strain assessments, assessment of congestive end-organ repercussion, as well as perioperative monitoring for air embolic burden.

\section{References}

1. Dávila-Román VG, Waggoner AD, Hopkins WE, Barzilai B. Right ventricular dysfunction in low output syndrome after cardiac operations: assessment by transesophageal echocardiography. Ann Thorac Surg. 1995;60:1081-6.

2. Maslow AD, Regan MM, Panzica P, Heindel S, Mashikian J, Comunale ME. Precardiopulmonary bypass right ventricular function is associated with poor outcome after coronary artery bypass grafting in patients with severe left ventricular systolic dysfunction. Anesth Analg. 2002;95:1507-18.

3. Haddad F, Hunt SA, Rosenthal DN, Murphy DJ. Right ventricular function in cardiovascular disease, part I: anatomy, physiology, aging, and functional assessment of the right ventricle. Circulation. 2008;117:1436-48.

4. Kormos RL, Teuteberg JJ, Pagani FD, Russell SD, John R, Miller LW, et al; HeartMate II Clinical Investigators. Right ventricular failure in patients with the HeartMate II continuous-flow left ventricular assist device: incidence, risk factors, and effect on outcomes. J Thorac Cardiovasc Surg. 2010;139: 1316-24.

5. Denault AY, Pearl RG, Michler RE, Rao V, Tsui SS, Seitelberger R, et al. Tezosentan and right ventricular failure in patients with pulmonary hypertension undergoing cardiac surgery: the TACTICS trial. J Cardiothorac Vasc Anesth. 2013; 27:1212-7.

6. Ternacle J, Berry M, Cognet T, Kloeckner M, Damy T, Monin JL, et al. Prognostic value of right ventricular two-dimensional global strain in patients referred for cardiac surgery. J Am Soc Echocardiogr. 2013;26:721-6.

7. Denault AY, Bussières JS, Arellano R, Finegan B, Gavra P, Haddad F, et al. A multicentre randomized-controlled trial of inhaled milrinone in high-risk cardiac surgical patients. Can J Anaesth. 2016;63:1140-53.

8. Singh A, Huang X, Dai L, Wyler D, Alfirevic A, Blackstone EH, et al. Right ventricular function is reduced during cardiac surgery independent of procedural characteristics, reoperative status, or pericardiotomy. J Thorac Cardiovasc Surg. 2020;159:1430-8.

9. Wranne B, Pinto FJ, Hammarstrom E, St Goar FG, Puryear J, Popp RL. Abnormal right heart filling after cardiac surgery: time course and mechanisms. Br Heart J. 1991;66:435-42.

10. Tamborini G, Muratori M, Brusoni D, Celeste F, Maffessanti F, Caiani EG, et al. Is right ventricular systolic function reduced after cardiac surgery? A two- and three-dimensional echocardiographic study. Eur J Echocardiogr. 2009;10: 630-4.

11. Lang RM, Badano LP, Mor-Avi V, Afilalo J, Armstrong A, Ernande L, et al. Recommendations for cardiac chamber quantification by echocardiography in adults: an update from the American Society of Echocardiography and the European Association of Cardiovascular Imaging. J Am Soc Echocardiogr. 2015;28:1-39.e14.

12. Denault AY, Vegas A, Lamarche Y, Tardif JC, Couture P, eds. Basic Transesopha geal and Critical Care Ultrasound. Boca Raton (FL): CRC Press; 2018.

13. Robitaille A, Denault AY, Couture P, Bélisle S, Fortier A, Guertin MC, et al Importance of relative pulmonary hypertension in cardiac surgery: the mean systemic-to-pulmonary artery pressure ratio. J Cardiothorac Vasc Anesth. 2006;20:331-9.

14. Bianco JC, Qizilbash B, Carrier M, Couture P, Fortier A, Tardif JC, et al. Is patient-prosthesis mismatch a perioperative predictor of long-term mortality after aortic valve replacement? J Cardiothorac Vasc Anesth. 2013;27:647-53.

15. Haddad F, Guihaire J, Skhiri M, Denault AY, Mercier O, Al-Halabi S, et al. Septal curvature is marker of hemodynamic, anatomical, and electromechanical ventricular interdependence in patients with pulmonary arterial hypertension. Echocardiography. 2014;31:699-707.

16. Rebel A, Nguyen D, Bauer B, Sloan PA, DiLorenzo A, Hassan ZU. Systemic-topulmonary artery pressure ratio as a predictor of patient outcome following liver transplantation. World J Hepatol. 2016;8:1384-91.

17. Bianco JC, Mc Loughlin S, Denault AY, Marenchino RG, Rojas JI Bonofiglio FC. Heart transplantation in patients $>60$ years: importance of relative pulmonary hypertension and right ventricular failure on midterm survival J Cardiothorac Vasc Anesth. 2018;32:32-40.

18. Denault AY, Chaput M, Couture P, Hébert Y, Haddad F, Tardif JC. Dynamic right ventricular outflow tract obstruction in cardiac surgery. $J$ Thorac Cardiovasc Surg. 2006;132:43-9.

19. Raymond M, Grønlykke L, Couture EJ, Desjardins G, Cogan J, Cloutier J, et al. Perioperative right ventricular pressure monitoring in cardiac surgery. J Cardiothorac Vasc Anesth. 2019;33:1090-104.

20. Vieillard-Baron A, Naeije R, Haddad F, Bogaard HJ, Bull TM, Fletcher N, et al Diagnostic workup, etiologies and management of acute right ventricle failure: a state-of-the-art paper. Intensive Care Med. 2018;44:774-90.

21. Sundaram V, Fang JC. Gastrointestinal and liver issues in heart failure. Circulation. 2016;133:1696-703.

22. Beaubien-Souligny W, Bouchard J, Desjardins G, Lamarche Y, Liszkowski M, Robillard P, et al. Extracardiac signs of fluid overload in the critically ill cardiac patient: a focused evaluation using bedside ultrasound. Can J Cardiol. 2017;33: 88-100.

23. Beaubien-Souligny W, Benkreira A, Robillard P, Bouabdallaoui N, Chassé M, Desjardins G, et al. Alterations in portal vein flow and intrarenal venous flow are associated with acute kidney injury after cardiac surgery: a prospective observational cohort study. J Am Heart Assoc. 2018;7:e009961.

24. Eljaiek R, Cavayas YA, Rodrigue E, Desjardins G, Lamarche Y, Toupin F, et al High postoperative portal venous flow pulsatility indicates right ventricular dysfunction and predicts complications in cardiac surgery patients. Br J Anaesth. 2019;122:206-14.

25. Couture EJ, Desjardins G, Denault AY. Transcranial Doppler monitoring guided by cranial two-dimensional ultrasonography. Can J Anesth. 2017;64:885-7.

26. Denault AY, Brassard P, Jacquet-Lagrèze M, Halwagi AE. Targeting optimal blood pressure monitoring: what's next? J Thorac Dis. 2018;10(Suppl 26): S3281-5. 